\title{
Removal of Iron (II) From Aqueous Solution by Cucurbita Moschata Peel Powder (CMPP)
}

\author{
Damascus Masawi ${ }^{1}$, Soloman Manyere ${ }^{2}$ and Mike Ngwebu ${ }^{3}$ \\ damascusmasawi@gmail.com,smanyere@gmail.com and mnngwebu@yahoo.com
}

Department of Bachelor of Technology in Chemical Technology in Affiliation with National University of Science and Technology (NUST), Harare Polytechnic, Box CY 407, Harare, Zimbabwe.

\begin{abstract}
The ability of butternut peel powder to adsorb Iron (II) from aqueous solutions was investigated. Batch studies were carried out to optimise $\mathrm{pH}$, contact time, sorbent dosage, and initial Iron (II) concentration at constant temperature of $25 \pm 1^{\circ} \mathrm{C}$ and agitation rate of $(120 \mathrm{rpm})$. The effect of initial iron (II)concentration was investigated under optimized conditions ( $\mathrm{pH} 9$, contact time of 90 minutes and dosage of $0.8 \mathrm{~g}$ ) and equilibrium data analysed using Langmuir and Freundlich parameters. The data fitted both Langmuir and Freundlich isotherm models, with a better fit in the Freundlich isotherm. The use of CMPP for the removal of Iron(II) can be implemented as a stand alone alternative to conventional methods to complement wastewater cleaning potentials.
\end{abstract}

Key words: Cucurbita moschata peel powder, Iron, Adsorption isotherm

\section{Introduction}

Contamination of water with heavy metals is a severe problem all over the world [1]. Water is exposed to numerous pollution by heavy metals from several industries such as mining activities, smelting and battery manufacture. The presence of heavy metals such as $\mathrm{Pb}, \mathrm{Cr}, \mathrm{Cu}$, $\mathrm{Fe}, \mathrm{Cd}, \mathrm{Hg}$ etc in waste water need to be treated appropriately as they will harm the ecosystem and public health[1]. Heavy metals are non-biodegradable and they cause various diseases and disorders[2].

Iron (II) is the fourth element of the earth's crusts one and the second most abundant metal in the earth[3]. Iron (II) is mainly present in ground water and also in surface water. The presence of Iron (II) in natural sources is due to the decomposition of rocks, acid mine drainage water, scrubbing of controlled discharges, effluents of the sewers and as well as industrial sectors. Excess Iron (II) causes degradation of water quality, corrosion and clogging of piping and reservoirs of water. Iron (II) containing water will stain laundry and utensil and will give astringent taste to water.[4]

Excess Iron (II) may result in debilitating and life threatening problems such as Cirrhosis, Liver Cancer, Cardiac arrhythmias, Diabetes, Alzheimer's disease and different bacterial, and viral infections. According to WHO the acceptable permissible level of Iron (II) in drinking water is $0.3 \mathrm{mgL}^{-1}$. The conventional methods used to remove heavy metals from waste water which includes, supercritical fluid extraction, bioremediation, oxidation with oxidising agent, chemical precipitation, ion exchange or membrane separation are either extremely expensive, too inefficient in reducing metal ion levels to permissible levels or generate toxic slurries

ACRID 2017, June 20-21, Victoria Falls, Zimbabwe

Copyright (C) 2017

DOI 10.4108/eai.20-6-2017.2271038 
whose disposal is problematic. Recent developments are focusing on biosorption which is a cost effective technique and simple to operate [5].

Recently researchers have concentrated their work on low cost, unconventional adsorbents for the treatment of wastewater. Agricultural wastes or derivates have generally been used as adsorbents in these studies. Some of the reported low cost adsorbents include saw-dust, bark and clay [7]. The abundance and availability of agricultural by-products make them good sources of adsorbents [7].

The main objective of the study was to investigate the feasibility of using CMPP, which is abundantly available in Zimbabwe, for the removal of Iron (II) from waste water.

\section{Experimental section}

\section{Biosorbent preparation}

Butternuts obtained from different suppliers in Zimbabwe were used in the research. $3 \mathrm{kgs}$ composite mixture of hand shelled butternut peels from the different suppliers were first thoroughly washed with tap then deionized water, oven dried at $105^{\circ} \mathrm{C}$ to constant mass, ground to powder using a pestle and mortar, and then screened through a $250 \mu \mathrm{m}$ sieve. For subsequent use in the research, the powder was sealed in polythene container to avoid moisture contamination.

\section{Reagents and solutions}

All chemical reagents used in this research were of analytical grade. Iron stock solution was obtained by dissolving 7.0223g ammonium ferrous sulphate in deionized water and diluted to $1000 \mathrm{~mL}$. Desired solutions concentration ranges were prepared by serial dilution of the stock solution.

\section{Batch studies}

Batch studies were carried out to investigate the effects of $\mathrm{pH}$, contact time, dosage and initial iron ion concentration which are the critical parameters which influence the adsorption process. Solution temperature and the rate of agitation were maintained constant throughout the study at $25 \pm 1^{\circ} \mathrm{C}$ and $120 \mathrm{rpm}$.

\section{Effect of $\mathbf{p H}$}

The effect of $\mathrm{pH}$ on the adsorption of iron using a constant mass of CMMP were carried out at varying $\mathrm{pH}$ values of $3,5,7,9$ and 11 using equal iron solutions volume concentrations in separate flasks. $\mathrm{pH}$ adjustment was made using $0.1 \mathrm{M} \mathrm{HCI}$ and $0.1 \mathrm{NaOH}$ solutions. The samples were agitated for $24 \mathrm{~h}$. The biosorbent was removed from the solution by filtration and the filtrate was analysed for residual concentrations using Ultraviolet visible Spectrophotometer at $540 \mathrm{~nm}$.

\section{Effect of contact time}

The adsorption experiments were carried out at increasing contact times from 30 to 150 minutes by contacting equal separate volume concentrations of iron solutions with a fixed adsorbent dosage of CMPP at $\mathrm{pH}$ 9. The samples were agitated, biosorbent removed from 
solution by filtration and the filtrate was analysed for residual concentrations using Ultraviolet visible Spectrophotometer at $540 \mathrm{~nm}$.

\section{Effect of adsorbent dosage}

The effect of adsorbent dosage was studied by agitating equal volume concentrations of iron solutions by varying amounts of CMPP biomass dosage ranging from $0.25 \mathrm{~g}$ to $1.25 \mathrm{~g}$ in separate flasks. The biosorbent was removed from solution by filtration and the filtrate was analysed for residual concentrations using Ultraviolet visible Spectrophotometer at $540 \mathrm{~nm}$.

\section{Effect of initial concentration}

The effect of initial concentration of iron solutions was examined under the optimum conditions by contacting $0.8 \mathrm{~g}$ samples of CMPP with constant separate volumes of iron solutions of different initial concentrations ranging from $50 \mathrm{ppm}$ to $200 \mathrm{ppm}$ at $\mathrm{pH}$ 9. The mixtures were agitated for 90 minutes. The biosorbent was removed from solution by filtration and the filtrate was analysed for residual concentrations using Ultraviolet visible Spectrophotometer at 540nm.

\section{Adsorption Equilibrium}

The initial and equilibrium concentrations of iron in solution were measured and the amount adsorbed was calculated from the mass balance equation 1 :

$Q_{e}=\mathrm{V}\left(C_{i}-C_{e}\right) / m$

Where $C_{i}$ and $C_{e}$ are the initial and equilibrium concentrations of Iron (II) ions in $\mathrm{mg} / \mathrm{L}$ respectively, Qe is the amount of Iron (II) ions adsorbed at equilibrium in $\mathrm{mg} / \mathrm{g}, \mathrm{V}$ is the volume of the Iron (II) solution in (L) and $\mathrm{m}$ is the mass of CMPP in grams. 


\section{Results and discussion}

\section{Effect of pH}

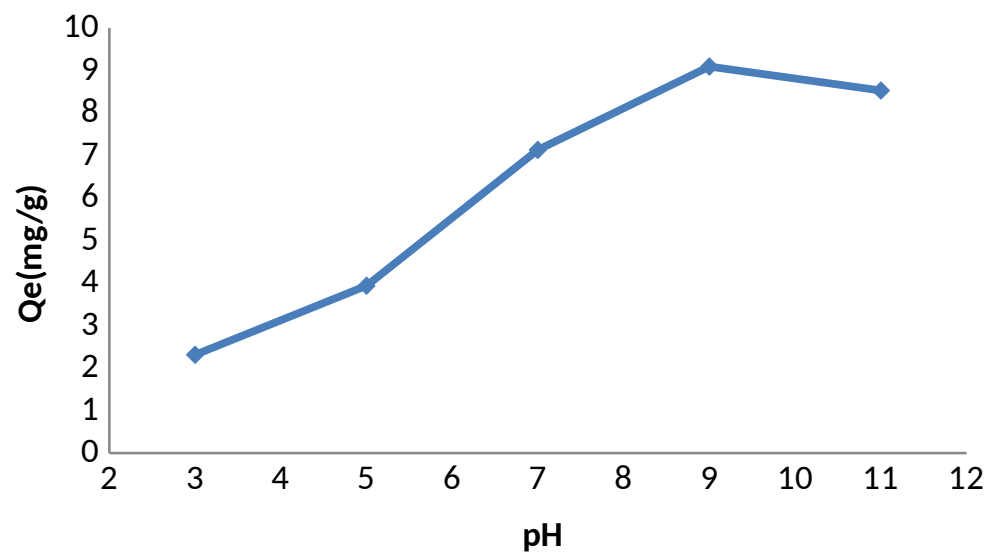

Fig. 1.Effect of $\mathrm{pH}$ on sorption

As the $\mathrm{pH}$ increases from 3 to 9 as shown in fig 1, there is a gradual increase in the adsorption of iron ions by CMMP up to a maximum adsorption at $\mathrm{pH} 9$ and at $\mathrm{pH}$ above 9 there is no significant increase. At low $\mathrm{pH}, \mathrm{H}^{+}$ions compete effectively with the iron ions to occupy adsorption sites on the adsorbent surface resulting in minimum adsorption of iron ions. As the $\mathrm{pH}$ increases to $\mathrm{pH}$ 9, the number of negatively charged sites on the CMMP surface increases and the number of positively charged sites decreases, which results in greater electrostatic attraction of iron ions by CMMP adsorbent surface[8].

\section{Effect of contact time}

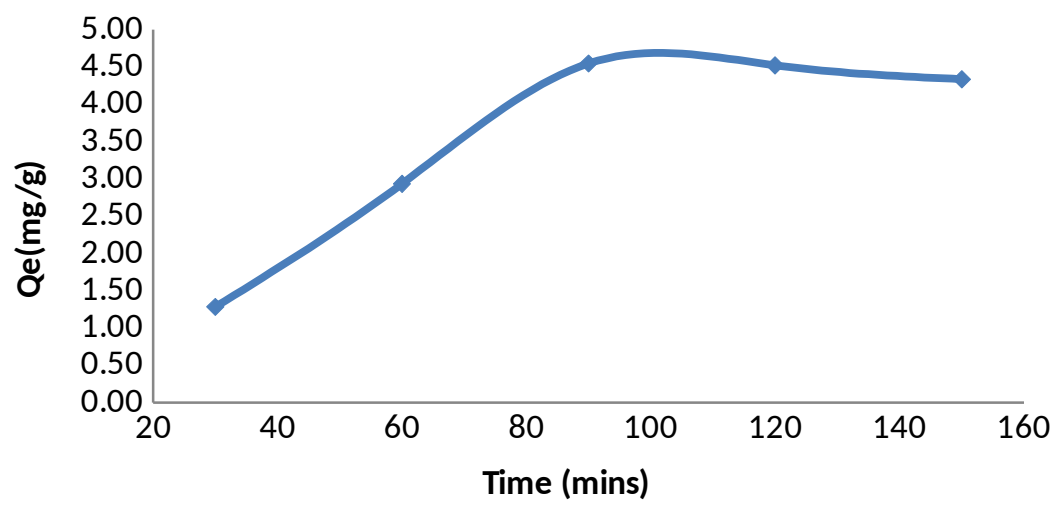

Fig. 2. Effect of contact time 
The adsorption increases rapidly at the initial stages, until it becomes constant at 90mins as shown in fig 2. At initial stages more adsorption sites will be readily available on the surface of CMPP [5]. As the time increases the adsorption sites gradually decreases as they get occupied resulting in constant diffusion gradient.

\section{Effect of biomass dosage}

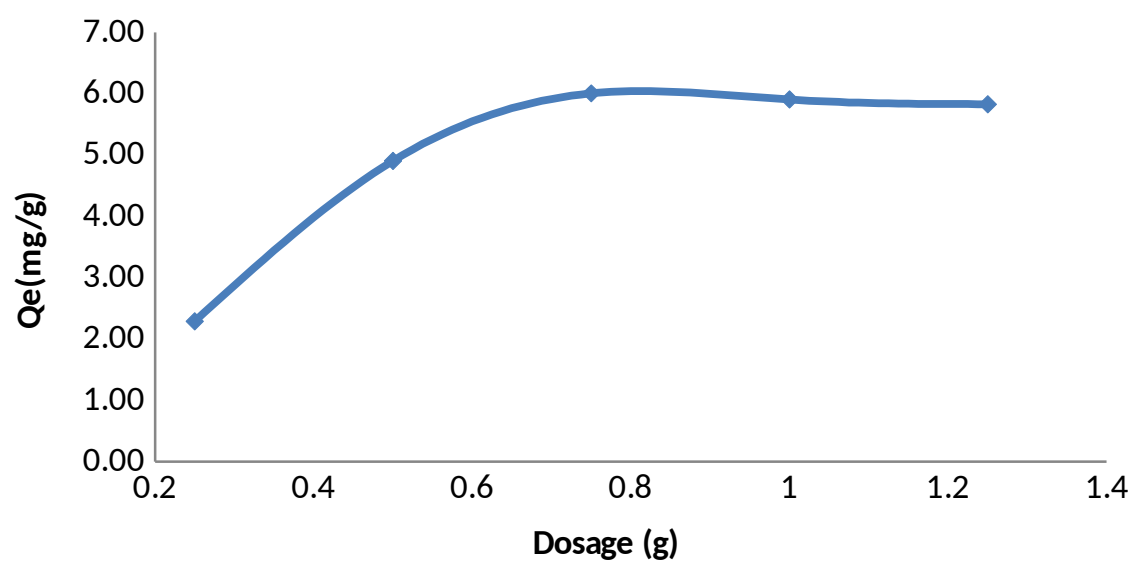

Fig.3. Effect of biomass dosage

As the biomass dosage increased the removal of iron ions increased to a constant value of $0.8 \mathrm{~g}$ CMMP as shown in fig 3. Increase in biomass dosage increases the adsorption surface area and further increase in CMPP above $0.8 \mathrm{~g}$ the removal efficiency of iron ions decreases because of saturation of the adsorbent surfaces[7]. 


\section{Effects of initial concentration}

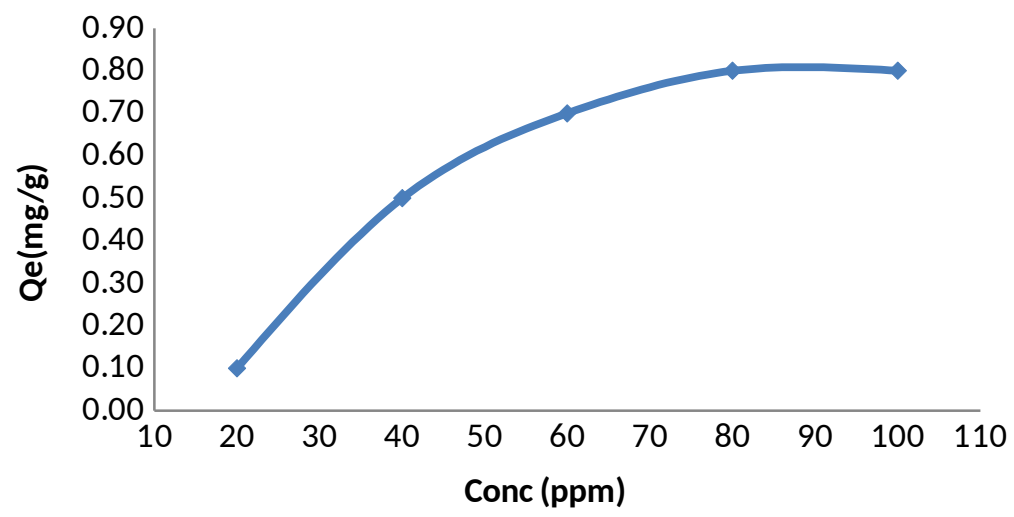

Fig. 4. Effect of initial concentration

The adsorption capacity increases as the iron ion concentration increases as shown in fig 4 to constant at $80 \mathrm{ppm}$. As the iron ion concentration increases the driving force to overcome mass transfer resistance increases between the adsorbent and adsorbate [3]. As the concentration increases above $80 \mathrm{ppm}$, the adsorption capacity decreases due to saturation of binding sites [6].

\section{Isotherm studies for CMPP}

The iron (II) uptake capacity of the CMPP was evaluated using the Langmuir and Freundlich adsorption isotherms. The Langmuir isotherm represents the equilibrium distribution of metal ions between the solid and liquid phases. The following equation can be used to model the adsorption isotherm

$\mathrm{q}_{\mathrm{e}}=\mathrm{q}_{\mathrm{m}} \mathrm{k}_{\mathrm{a}} \mathrm{c}_{\mathrm{e}} /\left(1+\mathrm{k}_{\mathrm{a}} \mathrm{C}_{\mathrm{e}}\right)$

where $\mathrm{q}_{\mathrm{e}}$ is milligrams of metal accumulated per gram of the biosorbent material; $\mathrm{C}_{\mathrm{e}}$ is the metal residual concentration in solution; $\mathrm{q}_{\mathrm{m}}$ is the maximum and $\mathrm{K}_{\mathrm{a}}$ is the Langmuir constant specific uptake corresponding to the site saturation and $\mathrm{b}$ is the ratio of adsorption and desorption rates[6]. The Langmuir isotherm is based on these assumptions [9]

- metal ions are chemically adsorbed at a fixed number of well defined sites;

- $\quad$ each site can hold only one ion;

- $\quad$ all sites are energetically equivalent and;

- there is no interaction between the ions; 
When the initial metal concentration rises, adsorption increases while the binding sites are not saturated. The linearised Langmuir isotherm allows the calculation of adsorption capacities and the Langmuir constants and is equated by the following equation.

$\mathrm{C}_{\mathrm{e}} / \mathrm{q}_{\mathrm{e}}=1 /\left(\mathrm{K}_{\mathrm{a}} \mathrm{q}_{\mathrm{m}}\right)+\mathrm{C}_{\mathrm{e}} / \mathrm{q}_{\mathrm{m}}$

The linear plots of $\mathrm{C}_{\mathrm{e}} / \mathrm{q}_{\mathrm{e}} \mathrm{vs} \mathrm{C}_{\mathrm{e}}$ show that adsorption follows the Langmuir adsorption model fig 5. The coefficient of determination, $\mathrm{R}^{2}$ is 0.982 . $\mathrm{q}$ max and $\mathrm{K}_{\mathrm{a}}$ were determined from the slope and intercept of the plot and were found to be $0.133 \mathrm{mg} / \mathrm{g}$ and $0.05 \mathrm{l} / \mathrm{mg}$ respectively.

The essential characteristics of the Langmuir isotherms can be expressed in terms of a dimensionless constant separation factor or equilibrium parameter, $\mathrm{R}_{\mathrm{L}}$, which is defined as:

$\mathrm{R}_{\mathrm{L}}=1 /\left(1+\mathrm{K}_{\mathrm{a}} \mathrm{C}_{0}\right)$

Where $\mathrm{K}_{\mathrm{a}}$ is the Langmuir constant and Co is the initial concentration of iron ions.

$R_{L}$ values between 0 and 1 indicate favourable adsorption. The $R_{L}$ were found to be 0.0022 which indicates favourable adsorption.

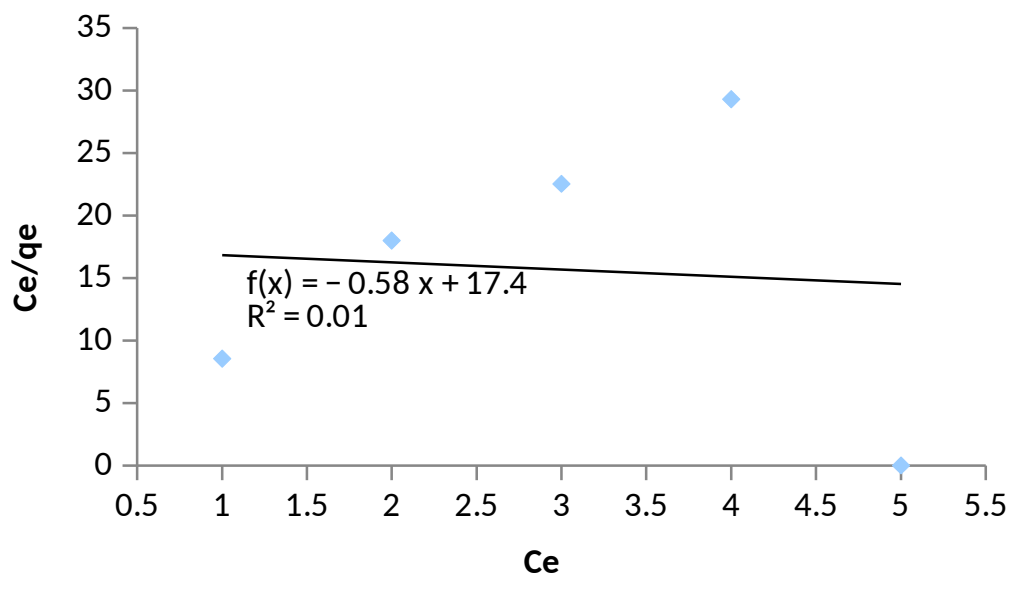

Fig .5. Langmuir isotherm for CMPP 


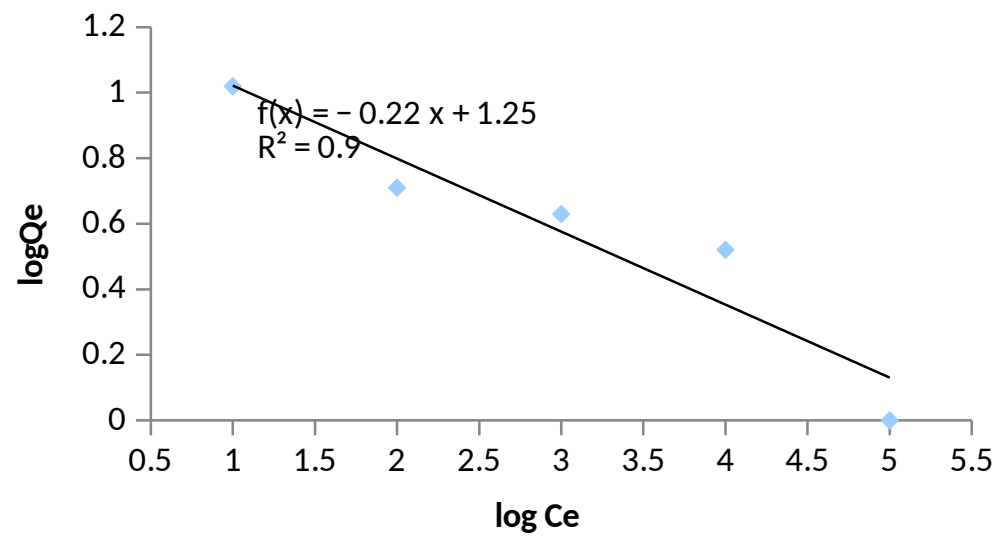

Fig.6. Freundlich isotherm for CMPP

The Freundlich isotherm equation is given as :

$\mathrm{q}_{\mathrm{e}}=\mathrm{K}_{\mathrm{F}} \mathrm{Ce} 1 / \mathrm{n}$

The linear form of the equation (4) is: $\operatorname{Ln} \mathrm{q}_{\mathrm{e}}=\operatorname{Ln} \mathrm{K}_{\mathrm{F}}+1 / \mathrm{n} \log \mathrm{Ce}$

Where: $\mathrm{q}_{\mathrm{e}}$ : the amount of adsorbate adsorbed at equilibrium $(\mathrm{mg} / \mathrm{g}), \mathrm{K}_{\mathrm{F}}$ and $\mathrm{n}$ : Freundlich constants, Ce: the equilibrium concentration of adsorbate in the solution. $\mathrm{K}_{\mathrm{f}}$ and $\mathrm{n}$ were calculated from the slopes of the Freundlich plot fig 6 . The constants were found to be $\mathrm{K}_{\mathrm{f}}=$ 15.84 and $\mathrm{n}=0.08$. The $\mathrm{n}$ value indicates the degree of nonlinearity between solution concentration and adsorption as follows: if $\mathrm{n}=1$, then adsorption is linear; if $\mathrm{n}<1$, then adsorption is a chemical process; if $\mathrm{n}>1$, then adsorption is a physical process. [7]

\section{Conclusion}

The present study shows that CMPP is an effective sorbent for the removal of iron ions from aqueous solutions. Maximum removal capacity is at $\mathrm{pH} 9$, and increases with increase of CMPP dose, of contact time and initial concentration. CMPP can be an alternative effective and inexpensive agro waste adsorbent that can be used in the removal of iron from waste water.

\section{References}

[1].Cho, B.Y.: Iron (II) removal using an aerated granular filter, Process Biochemistry. 40 (10), 3314--3320, (2005)

[2].Kurniawan, T. A., Chana, G.Y.S., Loa W.,Babel S.: Physico-chemical treatment techniques for wastewater laden with heavy metals, Chemical Engineering Journal. 118, 83-98 (2006) 
[3]. Popa,C., Bulai, P., Macoveanu M.: The study of Iron (II) (II) removal from 34\% calcium chloride solutions by chelating resin Purolite S930, J.Environmental Engineering and Management 1, 9 (5), 651--658, (2010).

[4]. Polat, H., Erdogan, D.: Heavy metal removal from waste waters by ion flotation. J. Hazardous Materials.148, 267--273, (2007).

[5].Smara, A., Delimi, R., Poinsignon, C.,Sandeaux J.: Electro extraction of heavy metals from diluted solutions by a process combining ion-exchange resins and membranes. Separation and Purification Technology. 44, 271--277, (2005)

[6].Tuzen,M., Uluozlu, O. D., Usta, C., Soylak,M.: Biosorption of copper(II), lead(II), Iron (II)(III) and cobalt(II) on Bacillus sphaericus-loadedDiaion SP-850 resin, Analytica Chimica Acta, 581, 241--246, (2007)

[7]. Veli, S., Alyuz, B.: Adsorption of copper and zinc from aqueous solutions by using natural clay, Journal of Hazardous Materials, 149,226--233, (2007).

[8]. Popa G., Moldoveanu S., Quantitative Chemical analysis using organics reagents, (in Romanian), Technical issue, Bucureti ,Romania(1969)

[9].Langmuir i., "The adsorption of gases on plane surfaces of glass, mica and platinum," The Journal of the American Chemical Society, vol. 40, no. 9, pp. 1361-1403(1918.) 